\title{
IT Governance Maturity: Developing a Maturity Model using the Delphi Method
}

\author{
Daniël Smits \\ University of Twente \\ d.smits@utwente.nl
}

\author{
Jos van Hillegersberg \\ University of Twente \\ j.vanhillegersberg@utwente.nl
}

\begin{abstract}
To advance in maturity, organizations should pay attention to both the hard and soft sides of IT governance (ITG). The hard side is related to processes and structure, the soft side to social aspects like behavior and organizational culture. This paper describes a study to develop an ITG maturity model (MM) that includes both.

Our research method is based on literature study, the Delphi method and makes use of a Group Decision Support System. We chose to design a focus area MM. In this type of MM maturity is determined by a set of focus areas.

The study reveals one MM as being appropriate for hard ITG. For soft ITG we found no single model appropriate. Soft governance needs more specific capabilities defined for each focus area individually. Based on knowledge from literature and experts we selected models for each focus area. Three alternatives for informal organization need further research.
\end{abstract}

\section{Introduction}

IT governance (ITG) is an ongoing concern for organizations worldwide. A McKinsey global survey in 2014 showed that $35 \%$ of IT executives (or $30 \%$ of all executives) mention "Improving governance processes and oversight" as most important to improving IT performance [1]. The CEB Audit Leadership Council has included ITG in their top 10 'hot spots' for 2014 mentioning that "The growing demand for information to enhance decision making has elevated the need for a comprehensive IT governance structure" [2].

ITG is a relatively new topic. The first publications appeared in the early 1990s [3]. Definitions of ITG in the literature vary greatly $[4,5]$. An analysis of the ITG literature revealed that six streams of thought can be distinguished in ITG [6]. These streams see ITG as:

1. decision making;

2. as part of IT auditing;
3. as part of corporate governance from a performance perspective;

4. as part of corporate governance from a conformance perspective; and

5. functioning top-down; or

6. functioning bottom-up.

Does ITG maturity have a significant positive impact on IT performance and firm performance? Some studies did not find a clear positive correlation $[7,8]$. Others, however, suggest a significant positive impact [9-12]. Some argue there might be a considerable time delay between the improvement of ITG maturity levels and the perceived benefit [13].

Frameworks frequently used in practice for ITG are very diverse: ITIL, security frameworks like ISO 17799, ISO 27000, ISO 38500, COBIT, Six Sigma, PMI/PMBOK, Risk IT, IT Assurance Framework, CMM or CMMI, and so on [14]. The foregoing underlines that in practice not only ITG frameworks are used for ITG but all sorts of frameworks.

These frameworks are largely based on processes and structure. An exception is the ISO 38500 standard for ITG [15]. This framework sets out six principles for good corporate governance of IT: acquisition, conformance, human behavior, Performance, responsibility, strategy. The inclusion of human behavior as one of the principles makes it a positive exception. Implementation of this standard however is not yet widespread $[14,16]$.

People are an important asset in organizations. People don't work or think in terms of process and structure only. Human behavior and organizational culture are equally important aspects of governance. A survey by the IT Governance Institute showed that "The culture of the organization, its ways of working and human factors" are seen by $50 \%$ of the participants as one of the factors that most influenced the implementation of ITG, surpassed only by "The business objectives or strategy" which scored 57\% [14]. 
To be able to grow in maturity, organizations should thus pay attention to the hard and soft aspects of governance. The split of governance into hard and soft governance has been made before [17-21]. Joseph Nye is founder of the soft power theory. Soft power is related to "intangible power resources such as culture, ideology, and institutions" [22]. This is close to how we see soft governance. We define the hard side of ITG as the functional aspects of governance like structure and processes. These aspects are also defined as the elements of organizational design. The soft side of ITG is defined as related to social aspects like human behavior and organizational culture.

The basic concept of a MM consists of a number of areas-henceforth called focus areas-which mature along a predefined path to achieve higher levels of maturity. A higher level of maturity is defined as a better means to fulfill its purpose; the predefined path is described by a set of capabilities. Capabilities are the ability to mobilize and deploy resources to achieve a goal [23].

Most maturity models (MMs) used for ITG are related to the existing frameworks mentioned before which are largely focused on processes and structure [24]. These frameworks make use of different approaches for assessing organizational maturity and performance. Some frameworks, for example COBIT, include a formal MM based on the CMM stages [25]. Others, for example ITIL, do not and need additional frameworks for maturity [26]. Of these frameworks, only COBIT is really focused on ITG.

MMs in which ITG is one of the areas can be found more often. Examples are the IT Capability Maturity Framework from the Innovation Value Institute [27]. This framework is based on the CMM levels too and contains maturity capabilities for IT leadership and governance.

The most dominant foundation of past IS research is CMM [28]. Perceptions on maturity differ. Some relate maturity to alignment with best practice frameworks. "A maturely governed IT organization is thus defined as an organization that is efficient and aligned with state-of-the-practice frameworks such as COBIT, Val IT or ITIL." [28].

An ITG MM for hard and soft governance does not exist $[14,28]$. We thus designed a new MM for ITG using knowledge from literature and experts. For this purpose we defined two research questions.

When designing a MM for ITG:

1. What type of MM do we need?

2. What are the capabilities of each focus area?

This paper is organized as follows. Section 2 presents the research methodology. Section 3 covers the MMs. The results of the literature study and the Delphi study are described in Section 4. The discussion and conclusion, including the limitations and next steps, are presented in Section 5.

\section{Research methodology}

There are many views on how to design a MM and no shared vision exists on which approach should be followed $[29,30]$. As a design process for the MM we combined the general process steps as described by Maier, Moultrie and Clarkson [31] for the design of maturity grids with the more specific process steps for the design of focus area maturity frameworks adapted from van Steenbergen et al. [32].

We combined this approach with a Delphi study. The Delphi method may be characterized as a method for structuring a group communication process so that the process is effective in allowing a group of individuals, as a whole, to deal with a complex problem [33]. The Delphi method is used to "generate propositions" on how focus areas grow in maturity and as "construct validation" [34]. The construct in this study is the MM.

As a foundation for the MM we built on an ITG model for hard and soft governance and the context of the organization [35] (see Table 1).

\section{Table 1. IT governance model foundation}

\begin{tabular}{|l|l|l|}
\hline Governance & Domain & Focus area \\
\hline \multirow{4}{*}{ Soft } & \multirow{2}{*}{ Behavior } & $\begin{array}{l}\text { Continuous } \\
\text { improvement }\end{array}$ \\
\cline { 3 - 3 } & \multirow{2}{*}{ Leadership } \\
\cline { 3 - 3 } & \multirow{3}{*}{ Collaboration } & Participation \\
\cline { 3 - 3 } & $\begin{array}{l}\text { Understanding and } \\
\text { trust }\end{array}$ \\
\hline \multirow{3}{*}{ Context } & \multirow{2}{*}{ Structure } & Functions and roles \\
\cline { 3 - 3 } & \multirow{2}{*}{ Process } & Formal networks \\
\hline & Internal & Ilanning \\
\cline { 3 - 3 } & External & Monitoring \\
\cline { 3 - 3 } & Informal organization \\
\hline
\end{tabular}

As proposed by several scholars, ITG can be deployed using a trichotomy summarized as structure, processes and relational mechanisms. This trichotomy was used as a starting point for the design. The domains for hard governance have been adopted. Relational mechanisms was broken up into several parts for soft governance and the context. Soft governance was divided into two domains 'Behavior' and 'Collaboration'. 'Behavior' defined as "the response of an individual" and 'Collaboration' defined as "making joint effort towards a goal", Within each domain focus areas were defined based on knowledge 
from literature and experts resulting in a set of nine focus areas.

The focus areas 'Culture', 'Informal organization' and 'Sector' are seen as value free and were moved to the context. The resulting 12 focus areas are the foundation for the MM we design in this study.

The approach of this study was to select existing MMs for each focus area of the IT governance model foundation (see Figure 1).

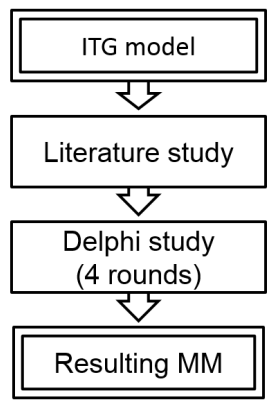

Figure 1. Overview of the study

In a literature study we made an initial selection of MMs for each focus area. The participants were asked to rate the suitability of the $\mathrm{MM}$ and received a handout with a summarized description of the proposed capabilities. Each round was organized as a meeting. After each round the model was improved using the feedback during the meeting.

Careful selection of participants is important. The quality and responses of a Delphi panel is as good as the experts $[33,36]$. For the series of meetings we invited participants very experienced in ITG. The average ITG experience was 13 years (for more details see Figure 4). These were found among the members of the special interest group Governance of the Ngi (the Dutch association of IT professionals) and the NAF workgroup IT governance $(\mathrm{NAF}=$ the Dutch Architecture Forum). The meetings were organized between October 2013 and February 2014. To invitees it was explained that it was important to attend the complete series of meetings.

\subsection{Technical details of the Delphi study}

The efficiency of face-to-face meetings was increased by a supplemental group communication process [33]. We used a Group Decision Support System (GDSS) to improve the effectiveness of the group meetings [37]. For this purpose we selected the innovative tool Spilter by Canast which is a userfriendly, web-based GDSS [38]. The tool also allows the researcher to enable anonymous responses for an individual question.
The participants had to respond to questions and statements using a laptop or tablet. There was no hierarchy or dominance; each opinion counted and was recorded. Where needed, responses were anonymous to the rest of the group. The upper part of the screen was available to all participants. What is shown on the lower part is highly configurable. If applicable, for example, when asked to rate a change in the model, we used Spilter to show graphs of the results after all responses were given (see Figure 2).

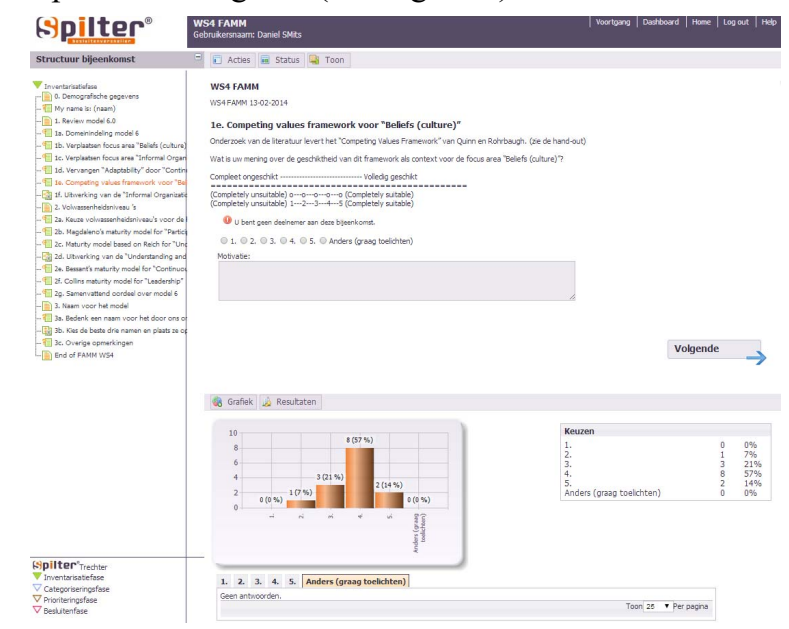

Figure 2. Example screenshot of Spilter

These graphs or intermediate results are only available to the researcher.

When experts invited to the meetings were not able to attend they were asked to give their feedback online at a later time using Spilter. In Spilter all feedback is traceable to the participant.

\section{Maturity models}

Merriam-Webster defines maturity as "the quality or state of being mature" [39]. The maturing entities in this study are 'organizational capabilities'. This is based on the resource-based-view which is used in strategic management literature [40, 41]. An organization capability is "the ability of an organization to perform a coordinated set of tasks, utilizing organizational resources, for the purpose of achieving a particular end result" [42].

MMs can be seen as artifacts to determine a company's status quo and as "deriving measures for improvement" [43]. The most well-known MM in the IT sector is the CMM. Version 1.0 of the model was published in 1991 [44, 45]. The interest in maturity emerged out of quality management [46]. In the 1930s Walter Shewhart started his work on process improvement with his principles of statistical quality 
control [47]. These principles were refined more than 50 years later by Deming, Crosby, and Juran [48-50].

Since the launch of CMM hundreds of MMs have been launched across a multitude of domains by researchers and practitioners [51, 52]. MMs are often modeled after CMMs distinguishing a fixed number of usually five generic maturity levels. Examples in literature are frequent, e.g. [10, 25, 53].

Since the introduction of CMM some changes have occurred. Fraser reviewed a number of maturity gridbased initiatives and concluded "it is clear that many different approaches have been adopted" [54].

CMM also has its critics $[55,56]$. They argue that there is too much focus in CMM on processes. Improving organizations requires attention to other aspects like people, culture or leadership too.

\subsection{Type of maturity model}

A systematic mapping study [57] showed that current MM research is applicable to more than 20 domains, heavily dominated by software development and software engineering. It shows that issues like IT alignment, the use of enterprise resource systems, technology and knowledge management, or collaboration processes, are becoming more important. The design of the MMs however "have only been documented very sketchily" [43]. Aims of MMs are "raising awareness" and "benchmarking" [31]. Awareness on what's going wrong and benchmarks to compare results across organizations. Thus MMs are helpful in finding better solutions for change. But to make them useful they must be applied to a substantial number of companies for valid comparison. Most MMs only enumerate maturity levels without considering the situational aspects of the organizational designs [29].

The answer to the question "What makes organizational capabilities mature?" depends on which rationale is embraced. Such rationale is usually about the leverage points used in organizational change initiatives [31]. Maier [31] discerns four leverage points that have been used in MMs:

1. existence and adherence to a structured process;

2. alteration of organizational structure;

3. emphasis on people;

4. and emphasis on learning.

The first two are related to hard governance, the latter two to soft governance. The MM described in this study is a hybrid of all four types. [58]:

Existing MMs can be divided into three basic types

1. Staged fixed-level models. Staged fixed-level models distinguish a fixed number of generic levels of maturity, usually around five.
2. Continuous fixed-level models. These differ from the staged fixed-level models in the fact that in the continuous models, focus areas are not attributed to a level, but the generic maturity levels are distinguished within each focus area.

3. Focus area models. This type of MM is based on the incremental improvement of a collection of focus areas to improve a domain.

Focus area models are much less common than fixed-level models. We share the view that different dimensions have different maturity levels and the assumption of the existence of generic maturity levels is an oversimplification. Thus we chose to design a focus area MM because they provide more guidance on incremental improvement than fixed-level MMs [32]. A distinguishing characteristic of a focus area MM is that it also defines the interrelated way focus areas grow in maturity (see Figure 3).

\begin{tabular}{|c|c|c|c|c|c|c|c|c|c|}
\hline Domain & Focus area & 1 & 2 & & 4 & 5 & 6 & 7 & ... \\
\hline Domain 1 & Area 1 & & A & & B & & & C & \\
\hline Domain 1 & Area 2 & A & & & & B & & & \\
\hline Domain 2 & Area 1 & & & & & & B & & c \\
\hline Domain 2 & Area 2 & & & & A & & & B & \\
\hline Domain 2 & Area 3 & & A & & & B & c & & D \\
\hline
\end{tabular}

Figure 3. Focus Area Maturity Model

Focus area MMs do not distinguish a fixed number of generic maturity levels, but instead define specific maturity levels for each focus area. The capabilities are numbered $\mathrm{A}, \mathrm{B}, \mathrm{C}$ and $\mathrm{D}$, as can be seen in the figure above.

The overall maturity of an organization is expressed as a combination of the specific maturity levels. The arrows in the right part of the figure show the interrelated way the capabilities can grow between the focus areas. The number of maturity levels is usually somewhere between 10 and 18 . The first two columns are the domains and focus areas which are relevant to the topic of the MM.

Furthermore, we decided to design a situational MM. Situational methods are methods configured specifically for the project at hand [59]. Several studies found that ITG is situational [14, 24, 60]. This implies that a one size fits all approach to ITG may not work in all circumstances [59]. Situational MMs are configured specifically for the (type of) organization or sector at hand [29].

\section{Results}

The number of participants at the first meeting was 19. Participation at the following meetings was only 
possible for this group of 19. A fourth meeting was added later in consultation with the participants (see Table 2).

\section{Table 2. Number of participants}

\begin{tabular}{|l|c|c|c|c|}
\hline Participation & WS1 & WS2 & WS3 & WS4 \\
\hline On location & 18 & 11 & 10 & 7 \\
\hline Online (afterwards) & 1 & 5 & 4 & 7 \\
\hline Total & 19 & 16 & 14 & 14 \\
\hline
\end{tabular}

The average age of the participants was 51 years. The group consisted of three women and 16 men. Eleven had a Master's degree, six a Bachelor's degree and two followed another type of education ('O'). A specific ITG training was attended by eleven participants (see Figure 4).

\begin{tabular}{|c|c|c|c|c|c|c|c|c|}
\hline 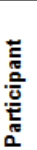 & 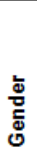 & $\stackrel{\Xi}{4}$ & 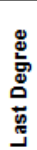 & Current position & 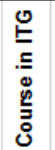 & 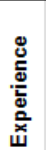 & 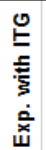 & 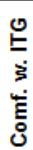 \\
\hline 1 & $M$ & 53 & $M$ & Information Manager & Yes & 25 & 15 & 5 \\
\hline 2 & M & 24 & M & Consultant Information Policy & No & 1 & 1 & 5 \\
\hline 3 & $\mathrm{~F}$ & 49 & M & Consultant & Yes & 14 & 14 & 7 \\
\hline 4 & M & 59 & M & Management Consultant & Yes & 34 & 26 & 7 \\
\hline 5 & M & 59 & $\mathrm{~B}$ & Auditmanager & Yes & 32 & 29 & 5 \\
\hline 6 & $\mathrm{~F}$ & 50 & $\mathrm{~B}$ & Operational Auditor & No & 31 & 11 & 2 \\
\hline 7 & M & 59 & $\mathrm{~B}$ & Interim Manager & No & 35 & 10 & 4 \\
\hline 8 & M & 40 & 0 & ICT Architect / Consultant & No & 14 & 3 & 1 \\
\hline 9 & M & 55 & B & Interim Manager & No & 30 & 3 & 2 \\
\hline 10 & M & 55 & $\mathrm{O}$ & Enterprise Architect & Yes & 25 & 10 & 6 \\
\hline 11 & M & 58 & M & Strategic Adviser & Yes & 35 & 10 & 5 \\
\hline 12 & M & 44 & $\mathrm{~B}$ & Management Consultant & Yes & 20 & 18 & 6 \\
\hline 13 & M & 55 & M & Director & No & 29 & 16 & 6 \\
\hline 14 & M & 57 & M & Informatie Manager $\mathrm{ClO}$ Office & No & 30 & 10 & 5 \\
\hline 15 & $\mathrm{~F}$ & 54 & M & Auditmanager & Yes & 26 & 26 & 5 \\
\hline 16 & M & 26 & M & Consultant & Yes & 3 & 3 & 6 \\
\hline 17 & M & 52 & $\mathrm{~B}$ & Advisor IT Governance ( $\mathrm{ClO}$ position) & No & 30 & 25 & 7 \\
\hline 18 & M & 61 & M & Consultant & Yes & 25 & 9 & 6 \\
\hline 19 & M & 54 & M & IT manager & Yes & 29 & 6 & 7 \\
\hline
\end{tabular}

Figure 4. Participant Demographics

The average years of work experience was 25 years of which 13 years with ITG. The self-reported average expertise with ITG was high: six on a scale of one to seven.

The hard and soft governance part of the MM made use of the capabilities as described in the sources listed. The context however was seen as value free. The MM does not contain capabilities for these areas. The context was used to assess the situational aspects. For this part of the model, frameworks (instead of MMs) were selected. To be used as conceptual structures that enable us to collect, collate and analyze the data for these focus areas.

\subsection{Hard governance}

In literature, the five-level ranking system introduced for CMM is often used for $\mathrm{MMs}$ for processes. In accordance with this we selected CMM for hard governance.
The CMM framework was selected because it is one of the most well-known and widely used MMs in the IT field. A CMM-like definition of capabilities in a focus area MM means each focus area will have the following five capabilities [44, 46]:
A. Initial level
B. Repeatable level
C. Defined level
D. Managed level
E. Optimizing level

Unlike CMM the levels will be numbered alphabetically as shown in figure 3 . The support by the experts for using CMM-like capabilities for hard governance was high (see Table 3 ).

Table 3. Hard governance

\begin{tabular}{|l|r|}
\hline Support for CMM [44] & \% \\
\hline 1. Completely unsuitable & 0 \\
\hline 2. Unsuitable & 0 \\
\hline 3. Indeterminate & 14 \\
\hline 4. Suitable & 57 \\
\hline 5. Completely suitable & 29 \\
\hline Average & 4.2 \\
\hline
\end{tabular}

With an average score of $4.2 \%$ the participants in the meeting largely agreed on the suitability of CMMlike capabilities for hard governance.

Not discussed during the meetings was the distinction between continuous and staged representation. In our MM, staged representation fitted best. Focus areas include more than just one process and a focus area MM does not contain incomplete capabilities. Level 0 in the continuous representation is "Incomplete", while the levels 1 to 3 are almost similar to the staged representation.

\subsection{Soft governance}

A MM for soft governance could not be found. During the first round we tried to select one MM for soft governance just as we did for hard governance. The support for CMM changed dramatically (7\%).

After the meeting we performed another literature study. We selected two MMs as alternatives. The MMs we selected were Magdaleno's Collaboration MM and Clark's Organizational Interoperability MM [61, 62]. The ratings of these MMs were also low. Support for Clark and CMM was low, 7\% and 7\%. Magdaleno scored a modest $21 \%$. The highest scores are for Different (36\%) and the Likert scale (29\%).

We changed our approach in the following round. The discussion showed that the participants preferred to select a specific MM for each focus area individually. This is in line with the concept of a focus area MM [32]. It was also a confirmation of our intention to design such a type of model. 
Where we could find more than one alternative (such as leadership) we selected the model which used a definition of the focus area closest to our definition.

There are large differences between MMs for leadership; they depend on the definition adopted. Our definition of leadership concerns behavior and the characteristics of the leader. There has been relatively little research into the characteristics of leaders whose teams and organizations beat the competition [63].

An exception is Collins [64], and thus we selected this research model. Collins surveyed the Fortune 1000 to identify companies that performed below the average of their business sector for 15 years and then performed above the average for 15 years. Only 11 companies fit this profile. It proved that their CEO's shared two characteristics: they show a compelling modesty and always do whatever must be done to produce the best long-term results, no matter how difficult.

It proved difficult to find usable MMs in the literature for some of the focus areas. For the focus area 'Understanding and trust' we could not find a suitable MM. For 'Understanding and trust' we suggested the use of a similar scale, as developed by Reich and Benbasat, for a study on the understanding between business and IT executives [65].

The results of the literature study are summarized in Table 4.

\section{Table 4. Selected sources (end result)}

\begin{tabular}{|l|l|}
\hline Focus area & Source \\
\hline Continuous improvement & Bessant et al [66] \\
\hline Leadership & Collins [64] \\
\hline Participation & Magdaleno et al [61] \\
\hline Understanding and trust & Reich et al [65] \\
\hline
\end{tabular}

The sources were intended to be used to deliver the description for the capabilities of each focus area. The support for the selected sources is shown in Figure 5.

\begin{tabular}{|c|c|c|c|}
\hline \multicolumn{2}{|l|}{ Continuous improvement } & \multicolumn{2}{|l|}{ Leadership } \\
\hline Support for Bessant et al [66] & $\%$ & Support for Collins [64] & $\%$ \\
\hline 1. Completely unsuitable & 0 & 1. Completely unsuitable & 0 \\
\hline 2. Unsuitable & 0 & 2. Unsuitable & \\
\hline 3. Indeterminate & 14 & 3. Indeterminate & 29 \\
\hline 4. Suitable & 43 & 4. Suitable & 43 \\
\hline 5. Completely suitable & 29 & 5. Completely suitable & 21 \\
\hline Different & 14 & Different & \\
\hline Average & 3.6 & Average & 3.8 \\
\hline \multicolumn{2}{|l|}{ Participation } & \multicolumn{2}{|c|}{\begin{tabular}{|l} 
Understanding and trust \\
\end{tabular}} \\
\hline Support for Magdaleno et al [61] & $\%$ & Support for Reich et al [65] & $\%$ \\
\hline 1. Completely unsuitable & 0 & 1. Completely unsuitable & 0 \\
\hline 2. Unsuitable & 14 & 2. Unsuitable & 7 \\
\hline 3. Indeterminate & 29 & 3. Indeterminate & 14 \\
\hline 4. Suitable & 57 & 4. Suitable & 50 \\
\hline 5. Completely suitable & 0 & 5. Completely suitable & 29 \\
\hline Different & 0 & Different & 0 \\
\hline Average & 3.4 & Average & 4.0 \\
\hline
\end{tabular}

Figure 5. Support for the stated sources
The participants were asked to rate the perceived suitability $(1=$ completely unsuitable, $5=$ completely suitable) of the capabilities defined in the framework for the purpose of the MM model.

The average suitability for the focus areas as rated by the participants was between 3.4 and 4.0 (on a scale of 5). The focus area 'Participation' scored lowest (3.4). One of the participants was of the opinion that Magdaleno's model could only be used at a micro scale. Two others suggested making a distinction between internal and external participation (the latter is not in scope).

The focus area 'Continuous improvement' scored remarkably high (3.6), especially because the name of this focus area was changed several times from 'Changeability' to 'Adaptability' and finally to 'Continuous improvement'; it took until the final round to reach a consensus. The average suitability of Collins' model was rated by the participants as 3.8.

Based on the stated sources the capabilities for each focus area can be characterized as described in the table. The first column is the focus area, the second and third the characterization of the capability belonging to succeeding maturity levels (Table 5).

Table 5. Capabilities of the MM (end result)

\begin{tabular}{|c|c|c|}
\hline Area & \# & Capability \\
\hline \multirow{5}{*}{ 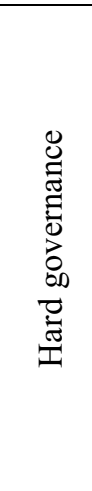 } & A & Processes are usually ad hoc and chaotic \\
\hline & B & $\begin{array}{l}\text { Processes are planned in accordance } \\
\text { with policy. }\end{array}$ \\
\hline & $\mathrm{C}$ & $\begin{array}{l}\text { Defined processes are used for managing } \\
\text { work. }\end{array}$ \\
\hline & $\mathrm{D}$ & $\begin{array}{l}\text { Quantitative objectives for quality and } \\
\text { process performance and use them as } \\
\text { criteria in managing processes. }\end{array}$ \\
\hline & $\mathrm{E}$ & $\begin{array}{l}\text { An organization continually improves its } \\
\text { processes based on a quantitative } \\
\text { understanding of its business objectives } \\
\text { and performance needs. }\end{array}$ \\
\hline \multirow{4}{*}{ 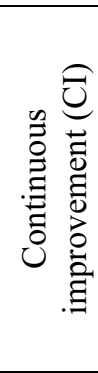 } & $\mathrm{A}$ & $\begin{array}{l}\text { Improvement requires a trigger and } \\
\text { implementation is on an ad hoc basis }\end{array}$ \\
\hline & B & $\begin{array}{l}\text { There is formal commitment to building } \\
\text { a system. }\end{array}$ \\
\hline & $\mathrm{C}$ & $\begin{array}{l}\text { CI behavior is established at a level } \\
\text { 'local to the wider strategic concerns of } \\
\text { the organization. }\end{array}$ \\
\hline & D & $\begin{array}{l}\text { Devolve autonomy and empower } \\
\text { individuals and groups. }\end{array}$ \\
\hline \multirow{3}{*}{ 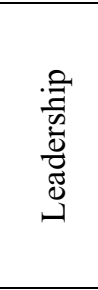 } & A & $\begin{array}{l}\text { Contributions through talent, knowledge } \\
\text { skills, and good work habits. }\end{array}$ \\
\hline & B & $\begin{array}{l}\text { Contributes to the achievement of group } \\
\text { objectives. }\end{array}$ \\
\hline & $\mathrm{C}$ & $\begin{array}{l}\text { Organizes people and resources toward } \\
\text { the effective and efficient pursuit of } \\
\text { predetermined objectives. }\end{array}$ \\
\hline
\end{tabular}




\begin{tabular}{|c|c|c|}
\hline Area & \# & Capability \\
\hline & $\mathrm{D}$ & $\begin{array}{l}\text { Catalyzes commitment to and vigorous } \\
\text { pursuit of a clear and compelling vision. } \\
\text { Personal humility and professional will. }\end{array}$ \\
\hline \multirow{4}{*}{ 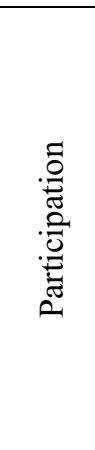 } & $\mathrm{A}$ & $\begin{array}{l}\text { Collaboration is dependent on individual } \\
\text { initiative. }\end{array}$ \\
\hline & B & $\begin{array}{l}\text { The role of the coordinator is needed to } \\
\text { centralize and to manage activities. }\end{array}$ \\
\hline & $\mathrm{C}$ & $\begin{array}{l}\text { Group members work in a self-organized } \\
\text { and simultaneous way. }\end{array}$ \\
\hline & $\mathrm{D}$ & $\begin{array}{l}\text { Group members are aware of the manner } \\
\text { in which the group collaborates during } \\
\text { process execution, while process (tacit) } \\
\text { knowledge is shared through ideas, } \\
\text { opinions and experiences. }\end{array}$ \\
\hline \multirow{3}{*}{ 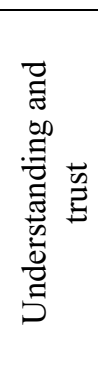 } & $\mathrm{A}$ & $\begin{array}{l}\text { Members can't identify each other's } \\
\text { major current objectives. }\end{array}$ \\
\hline & B & $\begin{array}{l}\text { Members have a general understanding } \\
\text { of each other's current objectives but } \\
\text { cannot identify specific, high-priority } \\
\text { ones. }\end{array}$ \\
\hline & $\bar{C}$ & $\begin{array}{l}\text { Members understand and are committed } \\
\text { to each other's mission, objectives, and } \\
\text { plans. }\end{array}$ \\
\hline
\end{tabular}

The maturity levels for 'Understanding and trust' are an elaboration of Reich's "Scale Used to Measure Understanding of Current Objectives" [65]. A focus area MM only contains capabilities. Reich defines the first level as "No mission, objectives, or plans have been formulated". It describes what is missing and cannot be seen as a capability. Thus the first level is not included in our MM. The average suitability for this focus area as rated by the participants was 4.0. Only the suitability of CMM for hard governance scored higher.

\subsection{The context}

For each focus area in the context (except the sector) we selected a framework. The results of the literature study are summarized in Table 6 .

Table 6. Selected sources (end result)

\begin{tabular}{|l|l|}
\hline Focus Area & Source \\
\hline Culture & Quinn et al. [67] \\
\hline Informal organization & Mintzberg [68]; \\
& Cobb [69]; \\
& Galbraith [70]. \\
\hline Sector & N/a \\
\hline
\end{tabular}

In the literature, frameworks are more common than maturity models. So there are a lot of options. For organizational culture, the Competing Values Framework (CVF) was selected [67]. The CVF "is probably the most frequently applied framework in the world for assessing culture" [71].
The CVF framework is based on an implicit theoretical framework by which the criteria of organizational effectiveness can be sorted according to three axes or value dimensions:

1. The first value dimension is related to organizational focus from an emphasis on the internal well-being and development of people to an external emphasis on the well-being and development of the organization itself.

2. The second value dimension is related to organizational structure, from an emphasis on stability to an emphasis on flexibility.

3. The third value dimension is related to organizational means and ends, from an emphasis on important processes to an emphasis on final outcomes.

The support for Quinn was measured using the same scale as shown in figure 5. This time the scores were 7\% 'Unsuitable', 21\% 'Indeterminate', 57\% 'Suitable' and $14 \%$ 'Completely suitable'. The rest was $0 \%$. This resulted in an average suitability as rated by the participants of 3.8. Thus in general the response to the framework was positive.

For the informal organization it was less clear which model should be used. We selected three alternatives to discuss during the meetings.

For 'Informal organization' three alternatives were proposed: the variables outlined by Cobb [69]; the seven types of lateral relations developed by Galbraith [70]; and the Sociogram as described by Mintzberg [68]. The variables outlined by Cobb were defined as the extent to which the respondent agreed that the target co-worker: was one of the nicest people he/she knew (referent); had good judgment and knew how to get things done in the workplace (expertise); could see to it that others were rewarded for their work (reward); could make things difficult for others (coercive); has legitimate organizational authority over the things done by co-workers (legitimate); had informal lateral influence among work unit peers; and had informal influence on the supervisor [69]. The seven lateral relations of Galbraith are: direct contact; liaison roles; task forces; teams; integrating roles; managerial linking roles; and the matrix organization [70]. The third alternative is the Sociogram. The Sociogram was defined by Mintzberg as "simply a map of who communicates with whom in an organization, without regard to formal channels" [68]. Each alternative was explained in a presentation and discussed during the workshop.

For the focus area 'Informal organization' we asked the participants to rate the suitability of the three alternatives (see Table 7). 
Table 7. Informal organization

\begin{tabular}{|l|c|c|c|}
\hline Support for source & \% & $\sigma$ & $\#$ \\
\hline 1. Five variables, Cobb [69] & 22.5 & 14.1 & 13 \\
\hline $\begin{array}{l}\text { 2. Lateral relations, Galbraith } \\
\text { [70] }\end{array}$ & 26.8 & 22.6 & 14 \\
\hline 3. Sociogram, Mintzberg [68] & 25.7 & 15.6 & 14 \\
\hline 4. Different & 25.0 & 36.2 & 5 \\
\hline
\end{tabular}

The second column shows the preference for the sources as a percentage. The third column shows the standard deviation between the answers $(\sigma)$. The final column (\#) shows the number of participants that assigned one or more points to a source. On request of the participants the option 'Different' was added including the option to explain this choice.

The results show no clear preference for one of these alternatives. Nine out of 14 participants assigned zero points to 'Different'. From this group the average score for Galbraith was 38\%; Mintzberg scored 33\%; and Cobb scored $28 \%$. The results for the informal organization didn't show a clear winner and the discussion afterwards did not reach consensus. The practitioners suggested finding out in practice which framework delivers the best results. It is clear this focus area needs additional research.

The 'Sector' focus area is out of scope for our research and was not mapped onto a framework.

\section{Discussion and conclusions}

The following discusses the answers to our research questions:

\section{What type of MM do we need?}

The study shows the participants defined different needs for the required $\mathrm{MM}$ for hard and soft governance. CMM seems adequate for hard governance. For soft governance it seems less appropriate. This finding is in line with the suggestion by several researchers that CMM does not effectively deal with the social aspects of organizations [56].

Soft governance needs different MMs for each focus area. This requirement can be fulfilled by designing a focus area MM. The context can be seen as the situational part of the MM. Research from Uehara showed that the Soft power theory could be applied to COBIT [20]. More specific to the processes of COBIT. We intent to apply it to the rest of the domains too.

\section{What are the capabilities of each focus area?}

The results of the Delphi study show a significant difference between the ways hard and soft governance grow in maturity. In the information systems field MMs are often modeled after CMM. For the hard side of governance this could be done in the same manner.
Soft governance showed a different picture. By contrast the literature study showed that the use of CMM in this area is less common. This was confirmed by the practitioners too. Furthermore they agreed that each focus should have its own capabilities based on different MMs.

The literature study showed that usable MMs for 'Continuous improvement', 'Participation' and 'Understanding and trust' are scarce. Where needed we selected the MMs which are close to the definitions in the ITG model used [35]. For 'Leadership' several alternatives are available. When focusing on the behavior of the leader relatively little research is available [63]. Collins is one of the exceptions [64]. The final results are stated in Table 4 and Table 5.

Literature and practice lead to the same conclusion: the way focus areas of hard and soft governance grow in maturity are different.

For the focus areas in the context we need a framework-instead of a MM- to access the organization. For culture and the informal organization lots of frameworks are available. Consensus could be reached for the use of the CVF for the focus area 'Culture' [67]. For the informal organization no consensus was reached. The rating by the practitioners for each alternative was approximately equal. Validation in practice is needed to find out which alternative delivers the best results.

\subsection{Limitations}

During the literature study we selected the best fitting MM within the available time limits and asked our group of experts to rate the suitability. This approach has the limitation that there might be other fitting MMs. Another limitation is that the composition of the group of Dutch experts might have impacted the resulting MM.

\subsection{Next steps}

MMs evolve over time, where, through continued use, difficulties or limitations may be revealed [31]. The transition from development to evaluation is fluid. By using the model in case studies we can gain feedback from the experience of companies to refine the MM iteratively.

During the case studies we can collect the information to determine the current state within several organizations. The information will be used in a longitudinal study too. After one or two years we plan to conduct another assessment and compare the results. 


\section{Acknowledgments}

We would like to thank the participants of the meetings for their contribution to the results and the reviewers for their review comments.

\section{References}

[1] Khan, N., and Sikes, J., IT under Pressure: Mckinsey Global Survey Results, McKinsey, 2014.

[2] Kann, R., Van Der Oord, F., Ugbah, J., Arora, A., and Kumar, N., 2014 Audit Plan Hot Spots, CEB Audit Leadership Council, 2013.

[3] Urbach, N., Buchwald, A., and Ahlemann, F., "Understanding IT Governance Success and Its Impact: Results from an Interview Study", AIS Electronic Library, 2013.

[4] Webb, P., Pollard, C., and Ridley, G., "Attempting to Define IT Governance: Wisdom or Folly?", IEEE, Kauai, HI, 2006, pp. 1-10.

[5] Lee, J., and Lee, C., "IT Governance-Based IT Strategy and Management: Literature Review and Future Research Directions", Information Technology Governance and Service Management: Frameworks and Adaptations, IGI Global, 2009, pp. 44-62.

[6] Smits, D., and Hillegersberg, J.V., "The Continuing Mismatch between IT Governance Theory and Practice: Results from a Delphi Study with CIO's", AIS Electronic Library, 2013.

[7] Tugas, F.C., "Information Technology Maturity Index and Profitability in the Philippine Food, Beverage and Tobacco Industry", International Journal of Business Research, 10(1), 2010.

[8] Tanriverdi, H., "Performance Effects of Information Technology Synergies in Multibusiness Firms", MIS Quarterly, 30(1), 2006, pp. 57-77.

[9] Liang, T.P., Chiu, Y.C., Wu, S.P.J., and Straub, D., "The Impact of IT Governance on Organizational Performance", AIS Electronic Library, 2011.

[10] Simonsson, M., Johnson, P., and Ekstedt, M., "The Effect of IT Governance Maturity on IT Governance Performance", Information Systems Management, 27(1), 2010, pp. 10-24.

[11] Dodds, R., "Effective Information Technology Governance Will Improve Returns to Shareholders", Information Systems Control Journal, 3, 2004, pp. 17-18.

[12] Weill, P., and Ross, J.W., IT Governance: How Top Performers Manage IT Decision Rights for Superior Results, Harvard Business Press, Boston, MA, 2004.

[13] Yuwono, B., and Vijaya, A., "The Impact of Information Technology Governance Maturity Level on Corporate Productivity: A Case Study at an Information Technology Services Company", IEEE, 2011, pp. 291-296.

[14] ITGI, "Global Status Report on the Governance of Enterprise IT (GEIT)", IT Governance Institute, Meadows, IL, 2011

[15] ISO/IEC 38500, "International Standard for Corporate Governance of IT", International Organization for Standardization (ISO) and the International Electrotechnical Commission (IEC), 2008.
[16] Couchman, P.K., Zutshi, A., Wilkin, C., Warren, M., and Sohal, A., "Corporate Governance and Information Technology: Findings from an Exploratory Survey of Australian Organizations", ANZAM, 2011, pp. 1-19.

[17] Moos, L., "Hard and Soft Governance: The Journey from Transnational Agencies to School Leadership", European Educational Research Journal, 8(3), 2009, pp. 397406.

[18] Tucker, C.M., The Lisbon Strategy and the Open Method of Coordination: A New Vision and the Revolutionary Potential of Soft Governance in the European Union, 2003, pp. 28-31.

[19] Cook, D.M., "The Use of Governance to Identify Cyber Threats through Social Media", International Cyber Resilience Conference, 2010, pp. 31-40.

[20] Uehara, K., "Soft IT Governance", ISACA Journal Online, 1, 2010, pp. 1-6.

[21] Tarmidi, M., Abdul Rashid, A., and Abdul Roni, R., "Exploring the Approaches for COBIT Process in Malaysian 100 Top Corporate Governance Companies", International Conference on Business and Economic Research, 2012, pp. 3081-3106.

[22] Nye, J.S., "Soft Power", Foreign Policy, 1990, pp. 153171.

[23] Bharadwaj, A.S., "A Resource-Based Perspective on Information Technology Capability and Firm Performance: An Empirical Investigation", MIS quarterly, 24(1), 2000, pp. 169-196.

[24] Rogers, G.P., "The Role of Maturity Models in IT Governance: A Comparison of the Major Models and Their Potential Benefits to the Enterprise", Information Technology Governance and Service Management: Frameworks and Adaptations, IGI Global, 2009, pp. 254-265.

[25] ITGI, COBIT® 4.1: Framework, Control Objectives, Management Guidelines, Maturity Models, IT Governance Institute, Meadows, IL, 2007.

[26] De Sousa Pereira, R.F., and Da Silva, M.M., "A Maturity Model for Implementing ITIL V3", IEEE, 2010, pp. 399-406.

[27] "Innovation Value Institute (IVI)", http://ivi.nuim.ie/.

[28] Pöppelbuß, J., Niehaves, B., Simons, A., and Becker, J., "Maturity Models in Information Systems Research: Literature Search and Analysis", Communications of the Association for Information Systems, 29(1), 2011.

[29] Mettler, T., and Rohner, P., "Situational Maturity Models as Instrumental Artifacts for Organizational Design", ACM, 2009, pp. 1-9.

[30] Pöppelbuß, J., and Röglinger, M., "What Makes a Useful Maturity Model? A Framework of General Design Principles for Maturity Models and Its Demonstration in Business Process Management", AIS Electronic Library, 2011.

[31] Maier, A.M., Moultrie, J., and Clarkson, P., "Assessing Organizational Capabilities: Reviewing and Guiding the Development of Maturity Grids", IEEE Transactions on Engineering Management, 59(1), 2012, pp. 138-159.

[32] Van Steenbergen, M., Bos, R., Brinkkemper, S., Van De Weerd, I., and Bekkers, W., "The Design of Focus Area Maturity Models" Global Perspectives on Design Science Research, Springer, 2010, pp. 317-332. 
[33] Linstone, H.A., and Turoff, M., "The Delphi Method: Techniques and Applications", MA, 1975.

[34] Okoli, C., and Pawlowski, S.D., "The Delphi Method as a Research Tool: An Example, Design Considerations and Applications", Information \& Management, 42(1), 2004, pp. 15-29.

[35] Smits, D., and Hillegersberg, J.V., "The Development of an IT Governance Maturity Model for Hard and Soft Governance", Academic Conferences and Publishing International Limited, 2014.

[36] Taylor-Powell, E., Quick Tips Collecting Group Data: Delphi Technique, University of Wisconsin, Madison, WI, 2002.

[37] Fjermestad, J., and Hiltz, S.R., "Group Support Systems: A Descriptive Evaluation of Case and Field Studies", Journal of Management Information Systems, 17, 2000, pp. 113-157. [38] http://www.spilter.nl/.

[39] http://www.merriam-webster.com/. Accessed 23 May 2014.

[40] Wernerfelt, B., "A Resource-Based View of the Firm", Strategic Management Journal, 5(2), 1984, pp. 171-180.

[41] Ulrich, D., and Smallwood, N., "Capitalizing on Capabilities", Harvard Business Review, 2004, pp. 119-128.

[42] Helfat, C.E., and Peteraf, M.A., "The Dynamic Resource-Based View: Capability Lifecycles", Strategic Management Journal, 24(10), 2003, pp. 997-1010.

[43] Becker, J., Knackstedt, R., and Pöppelbuß, J., "Developing Maturity Models for IT Management", Business \& Information Systems Engineering, 1(3), 2009, pp. 213222

[44] Paulk, M.C., Curtis, B., Chrissis, M.B., Averill, E.L., Bamberger, J., Kasse, T.C., Konrad, M.D., Perdue, J.R., Weber, C.V., and Withey, J.V., "Capability Maturity Model for Software", Carnegie Mellon University, Pittsburgh, PA, 1991.

[45] Paulk, M.C., "A History of the Capability Maturity Model for Software", ASQ Software Quality Professional, 12(1), 2009, pp. 5-19.

[46] SEI, "CMMI for Development, Version 1.3", Carnegie Mellon University, Pittsburgh, PA, 2010.

[47] Shewhart, W.A., Economic Control of Quality of Manufactured Product, ASQ Quality Press, 1931.

[48] Deming, W.E., Out of the Crisis, Massachusetts Institute of Technology Center for Advanced Engineering Study, Cambridge, MA, 1986.

[49] Crosby, P.B., Quality Is Free: The Art of Making Quality Certain, McGraw-Hill, New York, NY, 1979.

[50] Juran, J.M., Juran on Planning for Quality, Free Press New York, NY, 1988.

[51] De Bruin, T., Freeze, R., Kaulkarni, U., and Rosemann, M., "Understanding the Main Phases of Developing a Maturity Assessment Model", Australasian Conference on Information Systems, 2005, pp. 8-19.

[52] Weber, C., Curtis, B., and Gardiner, T., "Business Process Maturity Model (BPMM) Version 1.0", Needham, MA, 2008

[53] Grant, K.P., and Pennypacker, J.S., "Project Management Maturity: An Assessment of Project Management Capabilities among and between Selected Industries", IEEE Transactions on Engineering Management, 53(1), 2006, pp. 59-68.
[54] Fraser, P., Moultrie, J., and Gregory, M., "The Use of Maturity Models/Grids as a Tool in Assessing Product Development Capability", IEEE, 2002, pp. 244-249.

[55] Bach, J., "Enough About Process: What We Need Are Heroes", IEEE Software, 12(2), 1995, pp. 96-98.

[56] Ngwenyama, O., and Nielsen, P.A., "Competing Values in Software Process Improvement: An Assumption Analysis of CMM from an Organizational Culture Perspective", IEEE Transactions on Engineering Management, 50(1), 2003, pp. 100-112.

[57] Wendler, R., "The Maturity of Maturity Model Research: A Systematic Mapping Study", Information and Software Technology, 54(12), 2012, pp. 1317-1339.

[58] Van Steenbergen, M., Van Den Berg, M., and Brinkkemper, S., "A Balanced Approach to Developing the Enterprise Architecture Practice" Enterprise Information Systems, Springer, 2009, pp. 240-253.

[59] Brinkkemper, S., "Method Engineering: Engineering of Information Systems Development Methods and Tools", Information and Software Technology, 38(4), 1996, pp. 275280.

[60] Sethibe, T., Campbell, J., and Mcdonald, C., "IT Governance in Public and Private Sector Organizations: Examining the Differences and Defining Future Research Directions", AIS Electronic Library, 2007.

[61] Magdaleno, A.M., De Araujo, R.M., and Werner, C.M.L., "A Roadmap to the Collaboration Maturity Model (CollabMM) Evolution", IEEE, 2011, pp. 105-112.

[62] Clark, F.C., "IT Governance Involves Top Execs", Hospitals and Health Networks, 75(10), 2001, pp. 10-12.

[63] Kaiser, R.B., Hogan, R., and Craig, S.B., "Leadership and the Fate of Organizations", American Psychologist, 63(2), 2008, pp. 96-108.

[64] Collins, J., "Level 5 Leadership: The Triumph of Humility and Fierce Resolve", Harvard Business Review, 79(1), 2001, pp. 66-76.

[65] Reich, B.H., and Benbasat, I., "Measuring the Linkage between Business and Information Technology Objectives", MIS Quarterly, 20(1), 1996, pp. 55-81.

[66] Bessant, J., Caffyn, S., and Gallagher, M., "An Evolutionary Model of Continuous Improvement Behaviour", Technovation, 21(2), 2001, pp. 67-77.

[67] Quinn, R.E., and Rohrbaugh, J., "A Spatial Model of Effectiveness Criteria: Towards a Competing Values Approach to Organizational Analysis", Management Science, 29(3), 1983, pp. 363-377.

[68] Mintzberg, H., "The Structuring of Organizations: A Synthesis of the Research", University of Illinois at UrbanaChampaign's Academy for Entrepreneurial Leadership Historical Research Reference in Entrepreneurship, NJ, 1979. [69] Cobb, A.T., "Informal Influence in the Formal Organization: Perceived Sources of Power among Work Unit Peers", Academy of Management Journal, 23(1), 1980, pp. 155-161.

[70] Galbraith, J.R., "Organization Design: An Information Processing View", Interfaces, 4(3), 1974, pp. 28-36.

[71] Cameron, K.S., and R.E. Quinn, Diagnosing and Changing Organizational Culture: Based on the Competing Values Framework, John Wiley \& Sons, CA, 2011. 